\title{
Multicentre evaluation of the Thrombotest International Sensitivity Index used with a steel ball coagulometer
}

\author{
A $M$ H P van den Besselaar, R H M Peters
}

\begin{abstract}
Aim-To compare the International Sensitivity Index (ISI) of the Thrombotest reagent used with a steel ball coagulometer (KC) to the ISI of the same reagent used with the manual (tilt tube) technique.

Methods-The study was carried out by eight laboratories using their own $\mathrm{KC}$ instrument and method of testing. All laboratories used the same batch of Thrombotest to determine the clotting times of fresh blood samples from 20 local healthy volunteers and 60 patients on long term oral anticoagulant therapy. KC clotting times were plotted against manual clotting times on double logarithmic scales. Orthogonal regression lines were calculated to assess the ISI.

Results-In two laboratories the ISI of the KC method was lower than that of the manual method; these differences, however, were $2 \%$ or less. In the other laboratories no clinically important differences were observed between ISI values obtained. However, the clotting times determined with the KC methods were shorter than the manual values.

Conclusions-The ISI of Thrombotest determined with the $\mathrm{KC}$ methods was very similar to the manual value. Therefore, use of the ISI value supplied by the manufacturer without adjustment is justified. The mean normal prothrombin time, however, must be determined locally.

(f Clin Pathol 1996;49:414-417)
\end{abstract}

Keywords: international sensitivity index, international normalised ratio, oral anticoagulant control, prothrombin time.

Leiden University Hospital, Department of Haematology, Haemostasis and Thrombosis Research Centre, PO Box 9600 2300 RC Leiden, The Netherlands

A M H P van den

Besselaar

Hospital "De

Tjongerschans", Laboratory for Clinical Chemistry and Haematology, Thialfweg 44, 8441 PW Heerenveen, The Netherlands

R H M Peters

Correspondence to: Dr A M H P van den Besselaar.

Accepted for publication 1 February 1996

The recommended scale for reporting the prothrombin time in oral anticoagulant control is the international normalised ratio (INR). ${ }^{12}$ According to the calibration model adopted by the World Health Organisation, the INR can be calculated as follows:

$$
\mathrm{INR}=(\mathrm{PT} / \mathrm{MNPT})^{\mathrm{ISI}}
$$

where PT is the patient's prothrombin time, MNPT is the mean normal prothrombin time of fresh individual samples measured using the same method, and ISI is the international sensitivity index of the method used to measure the prothrombin time. The ISI should be provided by the manufacturer of the thrombo- plastin reagent. Some manufacturers include a conversion table for translating the prothrombin time into the INR, which should be used only if the MNPT of the individual laboratory is the same as that in the manufacturer's table. Several studies have shown that the ISI and MNPT are not a function of thromboplastin alone, but also of the method and coagulometer used..$^{3-8}$

In the Netherlands bovine brain thromboplastin combined with adsorbed bovine plasma (Thrombotest) is the most popular reagent used by anticoagulant clinics. ${ }^{9}$ At present, the manual (tilt tube) technique for determining the prothrombin time is used by two laboratories only $(2 \cdot 4 \%$ of all laboratories using Thrombotest). The most popular instrument is a semiautomatic coagulometer by which clotting is detected photo-optically. ${ }^{8}$ Another popular instrument is the steel ball coagulometer (KC, manufactured by Amelung, Lemgo, Germany) which is currently used by 16 laboratories (19\% of Thrombotest users). External quality assessment (EQA) data accumulated by the Federation of Dutch Thrombosis Centres showed that the Thrombotest clotting times determined by laboratories using $\mathrm{KCs}$ were shorter than those measured by other techniques. The manufacturer of Thrombotest provides only one ISI and MNPT value for each batch of reagent, which are based on the manual technique for venous blood samples.

The aim of the present study was to investigate whether there is a significant difference in the Thrombotest ISI used with the manual and $\mathrm{KC}$ methods.

\section{Methods}

APPARATUS

Four types of steel ball coagulometers were
REAGENT

Prothrombin times were measured using Thrombotest (manufactured by Nycomed AS, Oslo, Norway). A single batch (number 526) 
Table 1 Coagulometer methods used by participants

\begin{tabular}{llllll}
\hline Laboratory number & Coagulometer type & Sample volume $(\mathrm{ml})$ & Reagent volume $(\mathrm{ml})$ & Mode* & Incubation time (minutes) \\
\hline 1 & KC10 & 0.02 & $0 \cdot 100$ & SR & - \\
2 & KC10 & $0 \cdot 02$ & $0 \cdot 100$ & SR & - \\
3 & KC10 & $0 \cdot 02$ & $0 \cdot 100$ & SR & - \\
4 & KC10A & $0 \cdot 02$ & $0 \cdot 100$ & RS & 1 \\
5 & KC4A & 0.02 & $0 \cdot 100$ & SR & 3 \\
6 & KC10 & $0 \cdot 05$ & $0 \cdot 250$ & SR & 3 \\
7 & KC10 & 0.05 & $0 \cdot 250$ & SR & 1 \\
8 a & KC4 & 0.05 & $0 \cdot 250$ & SR & - \\
\hline
\end{tabular}

* Order of pipetting: $\mathrm{RS}=$ reagent, sample; $\mathrm{SR}=$ sample, reagent.

Table 2 Geometric mean clotting times (seconds) of fresh samples from patients and normal controls. Manual and KC clotting times were compared using the Student's paired $\mathrm{t}$ test

\begin{tabular}{|c|c|c|c|c|c|c|c|c|}
\hline \multirow[b]{2}{*}{ Laboratory number } & \multicolumn{4}{|c|}{ Normal controls } & \multicolumn{4}{|c|}{ Patients } \\
\hline & $n$ & Manual & $K C$ & $p$ value & $n$ & Manual & $K C$ & $p$ value \\
\hline $\begin{array}{l}1 \\
2 \\
3 \\
4 \\
5 \\
6 \\
7 \\
8 \mathrm{a} \\
8 \mathrm{~b}\end{array}$ & $\begin{array}{l}20 \\
20 \\
18 \\
20 \\
20 \\
20 \\
20 \\
20 \\
20\end{array}$ & $\begin{array}{l}39 \cdot 0 \\
40 \cdot 1 \\
38 \cdot 7 \\
38 \cdot 8 \\
36 \cdot 9 \\
36 \cdot 7 \\
38 \cdot 8 \\
39 \cdot 3 \\
39 \cdot 3\end{array}$ & $\begin{array}{l}34 \cdot 8 \\
36 \cdot 8 \\
34 \cdot 8 \\
37 \cdot 1 \\
34 \cdot 7 \\
33 \cdot 0 \\
35 \cdot 5 \\
35 \cdot 9 \\
38 \cdot 5\end{array}$ & $\begin{array}{l}<0.001 \\
<0.001 \\
<0.001 \\
<0.001 \\
<0.001 \\
<0.001 \\
<0.001 \\
<0.001 \\
<0.01\end{array}$ & $\begin{array}{l}60 \\
60 \\
57 \\
60 \\
60 \\
60 \\
59 \\
60 \\
60\end{array}$ & $\begin{array}{l}148 \cdot 5 \\
114 \cdot 8 \\
124 \cdot 1 \\
128 \cdot 1 \\
109 \cdot 3 \\
141 \cdot 9 \\
113 \cdot 5 \\
121 \cdot 1 \\
121 \cdot 1\end{array}$ & $\begin{array}{l}130 \cdot 3 \\
103 \cdot 6 \\
112 \cdot 8 \\
122 \cdot 2 \\
105 \cdot 7 \\
128 \cdot 7 \\
104 \cdot 5 \\
110 \cdot 6 \\
120 \cdot 8\end{array}$ & $\begin{array}{l}<0.001 \\
<0.001 \\
<0.001 \\
<0.001 \\
<0.001 \\
<0.001 \\
<0.001 \\
<0.001 \\
\text { NS }\end{array}$ \\
\hline
\end{tabular}

NS $=$ not significant at the $5 \%$ level; $n=$ number of subjects.

Table 3 Mean (SD) clotting times of three lyophilised control plasmas. Each laboratory provided 30 measurements for each plasmalmethod combination. The $S D$ is the within laboratory standard deviation

\begin{tabular}{|c|c|c|c|c|c|c|}
\hline \multirow[b]{2}{*}{ Laboratory number } & \multicolumn{2}{|l|}{ PN20 } & \multicolumn{2}{|l|}{$A k 110$} & \multicolumn{2}{|c|}{ Lot number $850618 \mathrm{~A}$} \\
\hline & Manual & $K C$ & Manual & $K C$ & Manual & $K C$ \\
\hline $\begin{array}{l}1 \\
2 \\
3 \\
4 \\
5 \\
6 \\
7 \\
8 \mathrm{a} \\
8 \mathrm{~b}\end{array}$ & $\begin{array}{l}37 \cdot 7(1 \cdot 3) \\
38 \cdot 4(1 \cdot 1) \\
39 \cdot 1(1 \cdot 2) \\
37 \cdot 8(0 \cdot 7) \\
38 \cdot 8(1 \cdot 1) \\
39 \cdot 5(1 \cdot 1) \\
40 \cdot 3(2 \cdot 1) \\
39 \cdot 1(1 \cdot 1)\end{array}$ & $\begin{array}{l}36.2(1.1) \\
36.9(0.8) \\
37.5(1.0) \\
37.4(0.7) \\
36.7(0.9) \\
36.9(0.9) \\
37.6(1.1) \\
37.1(0.6) \\
39.2(0.8)\end{array}$ & $\begin{array}{l}110(1 \cdot 7) \\
108(1 \cdot 2) \\
109(2 \cdot 2) \\
108(1 \cdot 7) \\
107(1 \cdot 6) \\
114(3 \cdot 4) \\
107(2 \cdot 7) \\
112(2 \cdot 3)\end{array}$ & $\begin{array}{l}103(1 \cdot 1) \\
106(1 \cdot 2) \\
100(4 \cdot 1) \\
107(1 \cdot 5) \\
103(1 \cdot 2) \\
107(1 \cdot 3) \\
104(2 \cdot 2) \\
107(1 \cdot 8) \\
112(1 \cdot 8)\end{array}$ & $\begin{array}{l}124(2 \cdot 1) \\
123(2 \cdot 2) \\
124(4 \cdot 2) \\
124(2 \cdot 1) \\
121(1 \cdot 2) \\
128(2 \cdot 7) \\
126(4 \cdot 0) \\
127(2 \cdot 4)\end{array}$ & $\begin{array}{l}121(2 \cdot 1) \\
124(0 \cdot 9) \\
119(7 \cdot 4) \\
124(1 \cdot 4) \\
119(0 \cdot 75) \\
121(1 \cdot 7) \\
124(2 \cdot 6) \\
125(2 \cdot 2) \\
129(2 \cdot 6)\end{array}$ \\
\hline Between laboratory CV (\%) & $2 \cdot 2$ & $2 \cdot 3$ & $2 \cdot 3$ & $3 \cdot 3$ & $1 \cdot 8$ & $2 \cdot 6$ \\
\hline
\end{tabular}

was used throughout the study. The ISI of this batch had been determined using the manual technique by calibration against OBT/79, the International Reference Preparation for thromboplastin, bovine, combined. ${ }^{9}$ The ISI of batch 526 was 0.97 . The reagent was reconstituted and used as recommended by the manufacturer.

\section{LYOPHILISED POOLED PLASMAS}

The following lyophilised pooled plasmas were used: Control Plasma Normal, batch number PN20 (Nycomed AS); Control Plasma from patients treated with oral anticoagulants, batch number AK110 (Immuno AG, Vienna, Austria); Control Plasma from patients treated with oral anticoagulants, batch number 850618A (Dutch Reference Laboratory for Anticoagulant Control, Leiden, The Netherlands). The plasmas were reconstituted and used as recommended by the manufacturers.

FRESH BLOOD SAMPLES

Blood samples were obtained from healthy subjects (normal controls) and from patients on long term oral anticoagulant treatment.
Nine volumes of blood were collected by venepuncture into siliconised glass or plastic tubes, containing one volume of $0 \cdot 11-0.13 \mathrm{~mol} /$ 1 trisodium citrate. The blood samples were stored at room temperature.

\section{DETERMINATION OF PROTHROMBIN TIME}

The prothrombin time was measured in citrated blood samples using the manual technique and by the $\mathrm{KC}$ method. The manual method (as recommended by the manufacturer) is as follows: $0.25 \mathrm{ml}$ Thrombotest reagent is heated in a glass tube in a waterbath at $37^{\circ} \mathrm{C}$ for at least three and at most 60 minutes. Then $0.05 \mathrm{ml}$ of sample is added and the timer is started. Clotting times were determined by the tilt tube technique.

The volumes of sample and reagent used for the $\mathrm{KC}$ method varied from laboratory to laboratory. Five used $0.02 \mathrm{ml}$ sample and $0.1 \mathrm{ml}$ Thrombotest reagent and the remainder used $0.05 \mathrm{ml}$ sample and $0.25 \mathrm{ml}$ reagent. Two different modes for the addition of sample and reagent were used. Two participating laboratories pipetted the reagent first, followed by the sample (RS mode). The remainder pipetted the sample first and then added preheated re- 
Table 4 Orthogonal regression line slopes and ISI values for the $K C$ method $\mathrm{v}$ the manual method. The $S D$ is the within laboratory standard deviation of the slope

\begin{tabular}{llll}
\hline Laboratory number & Slope $(S D)$ & $\begin{array}{l}\text { p value } \\
\text { (Null hypothesis slope=1.0) }\end{array}$ & $\begin{array}{l}\text { ISI } \\
\text { KC method }\end{array}$ \\
\hline 1 & $1.01(0.02)$ & NS & 0.98 \\
2 & $1.02(0.03)$ & NS & 0.99 \\
3 & $0.99(0.02)$ & NS & 0.96 \\
4 & $1.00(0.02)$ & NS & 0.97 \\
5 & $0.98(0.01)$ & p $<0.01$ & 0.95 \\
6 & $0.99(0.05)$ & NS & 0.96 \\
7 & $0.99(0.02)$ & NS & 0.96 \\
$8 \mathrm{a}$ & $0.99(0.02)$ & NS & 0.96 \\
$8 \mathrm{~b}$ & $0.98(0.02)$ & p<0.01 & 0.95 \\
\hline
\end{tabular}

agent (SR mode). In the latter mode the sample was incubated at $37^{\circ} \mathrm{C}$ for various times before the reagent was added. One laboratory used both modes. The methods are summarised in table 1 .

\section{STUDY DESIGN}

Each participant received a set of instructions and forms to report the measurement results. Every day for five days, each participant measured prothrombin times using both the manual and $\mathrm{KC}$ methods. The prothrombin times of the three lyophilised control plasmas were measured six times and the blood samples (four from normal controls and 12 from patients on anticoagulant treatment) in duplicate each day. Blood from different patients and controls was tested each day. The order of manual and KC testing alternated from day to day.

CALCULATIONS AND STATISTICAL METHODS

To calculate the ISI of the KC method, calibration lines were fitted by orthogonal regression ${ }^{1213}: y=a+b \times x$, where $y$ and $x$ are the logarithms of the prothrombin times of normal controls and patients determined by the manual and $\mathrm{KC}$ methods, respectively. The standard deviation of the slope $b$ was calculated as described by Van der Velde. ${ }^{13}$ The ISIs for the $\mathrm{KC}$ methods were derived by multiplication of the stated ISI value from the manual method with the value of the orthogonal regression slope $b$. To test whether the slope $b$ was equal to $1 \cdot 0$, we used the method described by Poggio et $a .^{3}$ Student's $t$ test was used for paired observations to assess the significance of differences in the prothrombin times measured using both methods. INR equivalents were calculated for the lyophilised plasmas using formula (1) and each laboratory's MNPT and ISI values.

\section{Results}

KC reaction conditions varied from laboratory to laboratory. Reagent and sample volumes, and the order in which the reagent and sample were added into the coagulometer cuvette differed, as did the incubation time used (table 1).

The mean clotting times of normal control and patient samples are given in table 2 . The clotting times measured using the $\mathrm{KC}$ method were shorter than those of the the manual technique except in laboratory number 8, which used the RS mode. The mean clotting times of the three lyophilised plasmas are given in table 3. The differences in clotting time between manual and $\mathrm{KC}$ methods were greater for the fresh blood samples than for the lyophilised plasma samples.

The slopes of the orthogonal regression lines relating $\mathrm{KC}$ to manual determinations are given in table 4. Only two slopes were significantly different from 1.0 at the $1 \%$ level of significance.

Laboratory number 8 used both the RS and SR modes of analysis, allowing comparisons to be drawn. The clotting times measured using the the SR mode were significantly shorter than those using either the RS mode or the manual method (table 2). The ISI value of the RS mode was significantly lower than that of both the manual technique (table 4 ) and the SR mode.

INR equivalents for the three lyophilised plasmas are given in table 5 . There was a trend to higher values for the $\mathrm{KC}$ methods compared with the manual method. The interlaboratory variation in the INR equivalents ranged from 3.0 to $4.2 \% \mathrm{CV}$

\section{Discussion}

The purpose of the present study was to compare the ISI of Thrombotest used with KC methods to the ISI of the same reagent used with the manual (tilt tube) technique. Although all of the participating laboratories used very similar KC instruments, the volumes of reagent and sample, mode of adding reagent and sample, and incubation times used differed (table 1). Despite these differences, the range of ISI values for the $\mathrm{KC}$ methods was rather narrow (table 4). In fact, the range of ISI values for the KC methods was smaller than that for the Lode micro method (1.00-1.07), as observed by Peters et al. ${ }^{8}$ The ISI of the KC

Table 5 INR equivalents for lyophilised plasmas

\begin{tabular}{|c|c|c|c|c|c|c|}
\hline \multirow[b]{2}{*}{ Laboratory number } & \multicolumn{2}{|l|}{ PN20 } & \multicolumn{2}{|l|}{$A K 110$} & \multicolumn{2}{|c|}{ Lot number $850618 \mathrm{~A}$} \\
\hline & Manual & $K C$ & Manual & $K C$ & Manual & $K C$ \\
\hline $\begin{array}{l}1 \\
2 \\
3 \\
4 \\
5 \\
6 \\
7 \\
8 \mathrm{a} \\
8 \mathrm{~b}\end{array}$ & $\begin{array}{l}0.97 \\
0.96 \\
1.01 \\
0.97 \\
1.05 \\
1.07 \\
1.04 \\
1.00 \\
-\end{array}$ & $\begin{array}{l}1.04 \\
1.00 \\
1.07 \\
1.01 \\
1.05 \\
1.11 \\
1.06 \\
1.03 \\
1.02\end{array}$ & $\begin{array}{l}2 \cdot 73 \\
2 \cdot 61 \\
2 \cdot 73 \\
2 \cdot 70 \\
2 \cdot 81 \\
3 \cdot 00 \\
2 \cdot 68 \\
2 \cdot 76 \\
-\end{array}$ & $\begin{array}{l}2 \cdot 90 \\
2 \cdot 85 \\
2 \cdot 75 \\
2 \cdot 79 \\
2 \cdot 81 \\
3 \cdot 09 \\
2 \cdot 81 \\
2 \cdot 85 \\
2 \cdot 76\end{array}$ & $\begin{array}{l}3.07 \\
2.97 \\
3.09 \\
3.09 \\
3.16 \\
3.36 \\
3.13 \\
3.12 \\
-\end{array}$ & $\begin{array}{l}3 \cdot 39 \\
3 \cdot 33 \\
3 \cdot 26 \\
3 \cdot 22 \\
3 \cdot 22 \\
3 \cdot 48 \\
3 \cdot 32 \\
3 \cdot 31 \\
3 \cdot 15\end{array}$ \\
\hline $\begin{array}{l}\text { Mean } \\
\text { Between laboratory CV (\%) }\end{array}$ & $\begin{array}{l}1 \cdot 01 \\
4 \cdot 1\end{array}$ & $\begin{array}{l}1 \cdot 04 \\
3 \cdot 3\end{array}$ & $\begin{array}{l}2 \cdot 75 \\
4 \cdot 2\end{array}$ & $\begin{array}{l}2 \cdot 85 \\
3 \cdot 6\end{array}$ & $\begin{array}{l}3.12 \\
3.6\end{array}$ & $\begin{array}{l}3 \cdot 30 \\
3.0\end{array}$ \\
\hline
\end{tabular}


methods was significantly different from the manual ISI in only two out of nine comparisons (table 4). Between laboratory variation in the ISIs for the KC methods is probably the result of variability in both the manual and semiautomated methods as the interlaboratory variation in the clotting times measured using these methods was very similar (table 3 ).

Most laboratories used the SR mode for the KC method (table 1). The RS mode was used by only two laboratories in this study. One of these (laboratory 8) used both modes. The results suggest that the clotting times obtained with the RS mode are closer to the manual clotting times than those of the SR mode. This may be explained by the fact that the manual method is also carried out in the RS mode. In this mode, the blood sample is at room temperature when it is added to the reagent. In the SR mode, the blood sample is first preheated at $37^{\circ} \mathrm{C}$. Therefore, in the manual method and the RS mode of the KC, the initial temperature of the reaction mixture is below $37^{\circ} \mathrm{C}$ and the initial reaction rate may be slightly lower than that of the SR mode.

We conclude that the ISI of the Thrombotest/ $\mathrm{KC}$ combination is practically the same as the ISI of the manual Thrombotest determination. Although we investigated only one batch of Thrombotest, we feel that the manual method ISI supplied by the manufacturer can be used with the semiautomated KC method. In contrast, the MNPT determined using the KC method is significantly shorter than that of the manual method and therefore the MNPT should be determined locally by each individual laboratory, as recommended previously. ${ }^{14} 15$

There is considerable interest in lyophilised plasmas because these are used in EQA schemes ${ }^{1617}$ and are also proposed as calibrants for local calibration of prothrombin time systems. ${ }^{1819}$ In both applications, it is assumed that lyophilised plasmas can replace fresh samples without influencing the relations between different prothrombin time systems. There is evidence that this assumption is not always true..$^{20-22}$ In the present study we included three lyophilised plasmas for quality control. INR equivalent values were calculated with method specific MNPT and ISI values. The INR equivalents determined with the KC methods were higher than those obtained with the manual methods (table 5). If INR equivalents assigned to these lyophilised plasmas are based on the manual technique and the $\mathrm{KC}$ method is calibrated using these values, the resulting calibration line would be biased and INRs of fresh samples read from this line would be underestimated. Further studies on the possible application of lyophilised calibrants are needed.

Participating laboratories were as follows: Rode Kruis Hospital, Beverwijk (J W Huisman); Hospital De Sionsberg, Dokkum (A P Anker); Sint Anna Hospital, Geldrop (R T P Jansen); Hospital De Tjongerschans, Heerenveen (R H M Peters); University
Hospital, Leiden (A M H P van den Besselaar); University Hospital, Maastricht (K Hamulyák); Sint Franciscus Hospital, Roosendaal (G D van Waveren Hogervorst); Sint Antonius Roosendaal (G D van Waveren

We thank Nycomed Pharma AS, Oslo, Norway, and their representatives in the Netherlands for providing the Thrombotest reagent and the control plasmas. The control plasma (lot number 850618A) provided by the Netherlands Reference Laboratory for Anticoagulant Control (RELAC) was prepared with support from the Netherlands Public Health Institute (Rijksinstituut voor Volksgezondheid en Milieuhygiene). Mrs E Witteveen, Mrs H Schaefer van Mansfeld and Mrs J MeeuwisseBraun provided excellent technical assistance.

1 Loeliger EA. International Committee for Standardization in Haematology and International Committee on Thrombosis and Haemostasis recommendations for reporting prothrombin time in oral anticoagulant control. Thromb prothrombin time in ora

2 WHO Expert Committee on Biological Standardization Thirty-third Report. WHO Tech Rep Ser 1983;687:81-105.

3 Poggio M, van den Besselaar AMHP, van der Velde EA, Bertina RM. The effect of some instruments for prothrombin time testing on the International Sensitivity Index (ISI) of two rabbit tissue thromboplastin reagents. Thromb Haemost 1989;62:868-74.

4 Van Rijn JLML, Schmidt NA, Rutten WPF. Correction of instrument- and reagent-based differences in determination of the International Normalized Ratio (INR) for monitoring anticoagulant therapy. Clin Chem 1989;35: $840-3$.

5 Ray MJ, Smith IR. The dependence of the International Sensitivity Index on the coagulometer used to perform the prothrombin time. Thromb Haemost 1990;63:424-9.

6 Poller L, Thomson JM, Taberner DA. Effect of automation on prothrombin time test in NEQAS surveys. $\mathcal{F}$ Clin Pathol 1989;42:97-100.

7 Chantarangkul V, Tripodi A, Mannucci PM. The effect of instrumentation on thromboplastin calibration. Thromb Haemost 1992;67:588-9.

8 Peters RHM, van den Besselaar AMHP, Olthuis FMFG. A multi-centre study to evaluate method dependency of the international sensitivity index of bovine thromboplastin. Thromb Haemost 1989;61:166-9.

9 Van den Besselaar AMHP. Use of lyophilized calibration plasmas and control blood for international normalized ratio calculation in external quality assessment of the prothrombin time. Am 7 Clin Pathol 1994;102:123-7.

10 Crespo B, Ankri A, Lesty C. Evaluation de l'appareil modulaire semi automatique de coagulation KC10. Nouv Rev Fr Hematol 1983;25:113-21.

11 Cambus JP, Biermé R, Laharrague P. Essai d'un coagulometre semi-automatique: le KC 10 (Etude de la coagulation sur plasma et sur sang total). Nouv Rev Med Toulouse 1983;1:851-6.

12 Hermans J, van den Besselaar AMHP, Loeliger EA, van der Velde EA. A collaborative calibration study of reference materials for thromboplastins. Thromb Haemost 1983;50: 712-17.

13 Van der Velde EA. Orthogonal regression equation. In: Van den Besselaar AMHP, Lewis SM, Gralnick HR, eds. Thromboplastin calibration and oral anticoagulant control. Thromboplastin calibration and oral antic

14 Peters RHM, van den Besselaar AMHP, Olthuis FMFG Determination of the mean normal prothrombin time for assessment of international normalized ratios. Usefulness of lyophilized plasma. Thrmb Haemost 1991;66:442-5.

15 Van den Besselaar AMHP, Lewis SM, Mannucci PM, Poller L. Status of present and candidate international reference preparations (IRP) of thromboplastin for the prothrombin time. A report of the subcommittee for control of anticoagulation. Thromb Haemost 1993;69:85.

16 Kitchen S, Walker ID, Woods TAL, Preston FE. Thromboplastin related differences in the determination of international normalised ratio: a cause for concern? Thrmb Hational normalised ratio:

17 Preston FE. Quality control and oral anticoagulation. Thromb Haemost 1995;74:515-20.

18 Clarke K, Taberner DA, Thomson JM, Morris JA, Poller L. Assessment of value of calibrated lyophilised plasmas to determine International Sensitivity Index for coagulometers. f Clin Pathol 1992;45:58-60.

19 Poller L, Thomson JM, Taberner DA, Clarke DK. The correction of coagulometer effects on international normalized ratios: a multicentre evaluation. $\mathrm{Br} f$ Haematol 1994;86:112-17.

20 Van den Besselaar AMHP, Bertina RM. Multi-center calibration of the second reference material for thromboplastin, rabbit, plain, coded CRM 149R. Thromb boplastin, rabbit, plain,
Haemost 1991;65:263-7.

21 Van den Besselaar AMHP, Bertina RM. Multi-center study of thromboplastin calibration precision. Influence of reagent species, composition, and international sensitivity index (ISI). Thromb Haemost 1993;69:35-40.

22 Van den Besselaar. AMHP. Multi-center study of replacement of the international reference preparation for thromboplastin, rabbit, plain. Thromb Haemost 1993;70: 794-9. 